\title{
A construção de casos de ensino em um programa de indução profissional: potencialidades formativas
}

\author{
The construction of teaching cases in a professional induction \\ program for beginning teachers: formative potentialities
}

\section{La construcción de casos de enseñanza en un programa de inducción profesional para principiantes: potencialidades formativas}

\author{
Nayana Cristina Gomes Teles' \\ Universidade Federal do Amazonas, Instituto de Ciências Exatas e Tecnologia, Professora \\ Adjunta. \\ https://orcid.org/0000-0002-5861-7674 \\ Fabrício Ualentim da Silua ${ }^{2}$ \\ Universidade Federal do Amazonas, Instituto de Ciências Exatas e Tecnologia, Professor \\ Adjunto. \\ https://orcid.org/0000-0001-8721-7103 \\ Tiago Pereira Gomes ${ }^{3}$ \\ Universidade Federal do Amazonas, Instituto de Ciências Exatas e Tecnologia, Professor \\ Assistente. \\ https://orcid.org/0000-0002-8324-3723
}

\begin{abstract}
Resumo: Este artigo tem por objetivos analisar o desenvolvimento profissional de professores iniciantes que participaram de um programa de indução profissional, considerando os casos de ensino construídos por esses professores e seus formadores que foram publicados em uma revista científica, e discutir as potencialidades dos casos de ensino na formação de professores. Diferentes autores (MARCELO GARCIA, 1999; IMBERNÓN, 2006; NONO; MIZUKAMl, 2002; MIZUKAMl, 2000; NONO, 2001, 2005) têm apontado os casos de ensino como um recurso importante para a formação de professores e para a investigação do desenvolvimento profissional docente. Parte-se da premissa que os casos de ensino, construídos a partir de situações reais vivenciadas em sala de aula permitem compreender as teorias pessoais dos professores sobre o ensino, bem como as crenças que influenciam sua atividade profissional, além do processo de construção e reconstrução do seu conhecimento profissional. Para
\end{abstract}

Doutora e Mestre em Psicologia da Educação pela Pontificia Universidade Católica de São Paulo.

Doutor em Educação pela Université de Montréal, Canadá; Mestre em Educação pela Universidade Federal de Uberlândia.

Mestre e doutorando em Educação pela Universidade Federal do Piauí. 
a análise dos casos de ensino, a metodologia escolhida foi a análise de conteúdo temático-categorial. Os autores construíram, a partir da revisão de literatura, uma matriz analítica organizada em unidades temáticas. A Unidade de Registro escolhida foi "frases com sentido completo". Foram analisados 13 artigos, selecionados por preencherem os requisitos de um caso de ensino, segundo a literatura adotada. A análise destes casos de ensino permite concluir que a experiência no Programa de Tutoria Educacional promoveu o desenvolvimento profissional dos professores tutorados, pois, nos casos de ensino analisados, os autores declaram, explicitamente ou não, mudanças de crenças pessoais dos professores sobre o ensino e/ou alunos e mudança e inovação das práticas.

Palavras-chave: Casos de ensino. Desenvolvimento profissional docente. Professores iniciantes. Indução profissional.

Abstract: This article aims to analyze the professional development of beginning teachers who have participated in a professional induction program considering the teaching cases constructed by these teachers and their trainers which were published in a scientific journal and to discuss the potential of teaching cases in the formation of teachers. Different authors ICARLOS MARCELO, 1999; IMBERNÓN, 2001; NONO; MIZUKAMI, 2002; MIZUKAMI, 2000; NONO, 2010) have pointed out teaching cases as an important resource for the training of teachers and the investigation of teacher professional development. It is based on the premise that teaching cases, constructed from real situations experienced in the classroom, allow to understand the personal theories of teachers about teaching, as well as the beliefs that influence their professional activity, in addition to the process of construction and reconstruction of their professional knowledge. For the analysis of teaching cases, the methodology chosen was the analysis of thematic-categorical content. From the literature review, the authors built an analytical matrix organized in thematic units. The unit of record chosen was "sentences with full meaning". Thirteen articles were analyzed, selected for fulfiling the requirements of a teaching case according to the adopted literature. The analysis of these teaching cases allows us to conclude that the experience in the Educational Tutoring Programme promoted the professional development of tutored teachers because in the analyzed teaching cases, the authors declare, explicitly or not, changes in teachers' personal beliefs and theories about teaching and/or students; change and innovation of practices.

Keywords: Teaching cases. Professional development. Beginning teachers. Professional induction.

Resumen: Este artículo tiene como objetivo analizar el desarrollo profesional de maestros principiantes que han participado en un programa de inducción profesional considerando los casos de enseñanza construidos por estos maestros y sus formadores que fueron publicados en una revista científica y discutir el potencial de los casos de enseñanza en la formación de docentes. Diferentes autores (CARLOS MARCELO, 1999; IMBERNÓN, 2001; NONO; MIZUKAMI, 2000; MIZUKAMI, 2004; NONO, 2010) han señalado los casos de enseñanza como un recurso importante para la formación de maestros y la investigación del desarrollo profesional docente. Se parte de la premisa de que los casos de enseñanza, construidos a partir de situaciones reales vividas en la sala de clase, permiten comprender las teorías personales de los maestros sobre la docencia, así como las creencias que influyen en su actividad profesional, además del proceso de construcción y reconstrucción. 
de sus conocimientos profesionales. Para el análisis de casos de enseñanza, la metodología elegida fue el análisis de contenido temático-categórico. A partir de la revisión de la literatura, los autores construyeron una matriz analítica organizada en unidades temáticas. La unidad de registro elegida fue "oraciones con pleno significado". Se analizaron trece artículos, seleccionados para cumplir con los requisitos de un caso de enseñanza de acuerdo con la literatura adoptada. $B$ análisis de estos casos de enseñanza permite concluir que la experiencia en el Programa de Tutoría Educativa promovió el desarrollo profesional de los maestros tutorados porque en los casos de enseñanza analizados, los autores declaran, de manera explicita o no, cambios en las creencias personales y teorías de los maestros sobre la docencia y / o estudiantes; cambio e innovación de prácticas.

Palabras clave: Casos de enseñanza. Desarrollo profesional. Maestros principiantes. Inducción profesional.

Recebido em 26 de janeiro de 2021 Aceito em 9 de março de 2021

\section{INTRODUÇÃO}

As discussões sobre o desenvolvimento profissional de professores iniciantes têm se destacado no contexto educacional, principalmente nos estudos de Nono e Mizukami (2002), Nono (2001, 2005), Mizukami (2000, 2002), Marcelo Garcia (1999), Imbernón (2006), Shulman (1992) e Alarcão (2011), que apontam os casos de ensino como instrumentos potentes na formação de professores e na investigação de processos de desenvolvimento profissional docente (DP).

Apesar desta potencialidade, o uso de casos de ensino nos processos de formação inicial e continuada, no Brasil, ainda é limitado e, mesmo no programa de indução profissional que deu origem às produções aqui analisadas, o potencial formativo e investigativo dos casos de ensino é subestimado.

Nono e Mizukami (2002, p. 72), ao buscarem definir o que é um caso de ensino, afirmam:

Normalmente, um caso é definido como um documento descritivo de situações reais ou baseadas na realidade, elaborado especificamente para ser utilizado como ferramenta no ensino de professores. Trata-se de uma representação multidimensional do contexto, participantes e realidade da situação. É criado explicitamente para discussão e procura incluir detalhes e informações suficientes para permitir que análises e interpretações sejam realizadas a partir de diferentes perspectivas. 
A elaboração de casos de ensino é uma estratégia formativa importante tanto para quem o escreve, como para os professores e futuros professores que a eles têm acesso. Para os docentes que os produzem, potencializa a reflexão crítica sobre sua prática, além de mobilizar os conhecimentos implicados nas decisões pedagógicas tomadas, que podem ser revistas e redirecionadas. Como instrumento na formação de futuros professores, os casos de ensino aproximam os estudantes das situações concretas encontradas na sala de aula, auxiliando-os a

\footnotetext{
[...] relacionar teoria e prática; encontrar saídas e resolver problemas em situações dilemáticas; interpretar situações a partir de múltiplas perspectivas; reconhecer riscos e vantagens presentes em cada forma de agir; identificar e testar princípios teóricos em situações reais de sala de aula. (NONO; MIZUKAMl, 2002, p. 72).
}

A intenção de discutir a potencialidade dos casos de ensino na formação encontra amparo nas contribuições de Imbernón (2006) acerca da importância da formação centrada na escola. Para esse autor, não se trata de descartar outros lugares e ações formativas, ou estar, geograficamente, acontecendo na escola, mas pensar a formação dentro da profissão, tendo como referência a escola, lugar prioritário para a formação dos futuros professores.

Dessa maneira, este estudo tem como objetivos analisar o DP de professores iniciantes que participaram de um programa de indução profissional, considerando os casos de ensino construídos por estes professores e seus formadores e publicados em uma revista científica, bem como analisar as potencialidades dos casos de ensino na formação, inicial e continuada, de professores. 0 conceito de indução, de acordo Cruz, Farias e Hobold (2020, p. 6), se refere "[...] ao processo de acompanhamento do professor iniciante ou principiante durante a sua inserção profissional [...]", acrescentamos ainda, que é uma ação formativa voltada para a aquisição de conhecimentos e competência profissional por parte do professor iniciante, que tem necessidade de ações sistematizadas de acompanhamento ao trabalho docente durante os primeiros anos de exercício na profissão.

Após essa breve introdução com a contextualização da temática e os objetivos, apresenta-se uma sucinta descrição do programa de formação de professores iniciantes, locus de produção dos casos aqui analisados, e, em seguida, uma discussão dos princípios fundamentais da análise realizada: o conceito de DP e as particularidades do início da carreira docente. 


\section{O PROGRAMA DE INDUÇÃO PROFISSIONAL DE PROFESSORES DA SEMED/MANAUS}

A Secretaria Municipal de Educação de Manaus (SEMED/Manaus) é uma das poucas secretarias de educação no Brasil que oferece um programa de indução voltado ao atendimento dos docentes em estágio probatório na rede municipal, independente de possuírem ou não experiências no ensino (GATTl et al., 2019).

Esta Secretaria tem se destacado no cenário nacional por oferecer um amplo leque de atividades de formação continuada (FC) aos docentes da rede municipal, atividades estas que vão ao encontro de muitos dos critérios hoje discutidos na literatura da área como necessários a uma FC eficaz (MORICONI et al., 2017).

As atividades de FC destinadas aos professores da SEMED/Manaus são desenvolvidas considerando, duas estratégias. Na primeira, denominada formação centrada na escola, o formador vai até a escola e lá desenvolve a FC. Dentro dessa estratégia, encontra-se o Programa Oficinas de Formação em Serviço (POFS), realizado em parceria com a Universidade do Estado do Amazonas (UEA), e o Programa de Tutoria Educacional (PTE), realizado em parceria com a Fundação Itaú Social (FIS). A segunda estratégia busca atender a um número maior de professores, bem como os professores das escolas ribeirinhas e/ou de difícil acesso. São as formações em polo, nas quais o professor se desloca da escola para o polo de formação.

0 PTE, locus de produção dos textos aqui analisados, tem por objetivo fortalecer as práticas educativas por meio da formação em serviço, contando com acompanhamento pedagógico e avaliação gradativa dos professores em estágio probatório. Assim, a Tutoria Educacional (TE) pode ser definida como uma metodologia de formação em serviço, realizada no cotidiano da escola por um profissional mais experiente, que reconhece, valoriza e parte dos conhecimentos e da vivência do tutorado, para desencadear o processo de aprendizagem (FUNDAÇÃO ITAÚ SOCIAL, [20--]).

Baseado em uma relação de parceria e corresponsabilidade entre tutor lo par experiente) e tutorado (o professor iniciante), a TE privilegia o cotidiano da escola e parte das necessidades do professor em sua prática de sala de aula, para o desenho da FC. 0 PTE parte da premissa de que as políticas que conseguem mudanças dentro da sala de aula requerem a formação contínua dos professores. Portanto, e esse é um dos pilares da TE, a FC precisa tomar as práticas diárias dos professores nas escolas como ponto inicial do processo formativo (FUNDAÇÃO ITAÚ SOCIAL, [20--]).

$\mathrm{Na}$ metodologia da TE, a rotina de trabalho do tutor baseia-se em alguns princípios, descritos no Guia de Tutoria de Área (FUNDAÇÃO ITAÚ SOCIAL, [20--], p. 8). São eles: aprendizagem na prática, parceria, customização, protocolos e combinados, intencionalidade e 
transparência e foco na aprendizagem dos alunos. 0 primeiro passo no processo de TE é a realização de um diagnóstico pelo tutor, que identifica os pontos fortes e fracos do tutorado, as competências que precisa desenvolver e seu estilo de aprendizagem.

De posse do diagnóstico inicial, o tutor dialogará com o seu tutorado acerca do que observou e construirá com ele um plano de formação. Na construção do plano de formação, tutor e tutorado precisam definir as áreas prioritárias do seu DP passíveis de serem trabalhadas em um determinado período de tempo. Embora o plano seja um instrumento vivo e aberto, prazos e combinados precisam ser estabelecidos entre tutor e tutorado, e o plano será "[...] a referência para se avaliar os avanços e os desafios do trabalho de tutoria." (FUNDAÇÃO ITAÚ SOCIAL, [20--], p. 15).

Uma vez realizado o diagnóstico e elaborado o plano de formação, as reuniões de trabalho da tutoria podem ter início. A metodologia da FIS propõe seis estratégias para nortear o trabalho do tutor: observação, feedback, caminhadas pedagógicas pela escola, role play, ação modelar e comunicação: escuta ativa e questionamento, todas descritas no Guia de Tutoria de Área. Esse guia traz um passo a passo da rotina de trabalho do tutor de área acompanhado de instruções de como executar cada passo (FUNDAÇÃO ITAÚ SOCIAL, [20--], p. 40).

Os professores admitidos através de concurso pela SEMED/Manaus são acompanhados pelos tutores (formadores de professores) durante um ano, com encontros semanais, e, ao final da participação no Programa, são convidados a produzir, junto com seus tutores, um artigo científico que retrate uma experiência de prática docente desenvolvida durante a tutoria, a ser apresentado no encontro Socialização de Práticas Formativas, realizado, anualmente, pela Divisão de Desenvolvimento Profissional do Magistério (DDPM) da SEMED/Manaus, considerado a culminância dos processos formativos. Os melhores artigos são selecionados e publicados na Revista Eletrônica Mutações, publicada pela Universidade Federal do Amazonas (UFAM).

Chama a atenção o fato de a produção de artigos ou escrita de casos de ensino não ser uma estratégia prevista na TE, constituindo-se em uma iniciativa original da SEMED/ Manaus. A análise de 219 artigos publicados na Revista Eletrônica Mutações permite afirmar que os escritos têm grande potencial formativo, e, embora apenas 13 artigos que serão aqui analisados preencham os requisitos necessários para serem denominados casos de ensino, o texto aqui produzido pode contribuir para o enriquecimento de produções futuras. 


\section{O DESENUOLUIMENTO PROFISSIONAL DE PROFESSORES INICIANTES}

Ao longo de sua trajetória profissional, os professores passam por diferentes etapas ou fases com características distintas. Entretanto, reconhecer esses diferentes momentos, fortemente marcados pelo percurso profissional e pessoal do professor, não implica desconsiderar que a formação docente deve ser realizada de maneira integrada, na perspectiva de um DP que se estende ao longo da vida, como um continuum.

Assim, a opção pelo uso dos termos formação inicial e formação continuada é válida para demarcar etapas distintas do percurso profissional do professor e para nos referirmos a processos formativos institucionalizados, que, em geral, ocorrem na universidade e na escola, respectivamente. Porém, o processo de aprendizagem da profissão, o DP do professor, prescinde dessas fronteiras e inclui aprendizagens formais e informais, planificadas ou não (DAY, 2001, p. 16).

Day (2001, p. 21) define o DP como

[... o processo através do qual os professores, enquanto agentes de
mudança, reveem, renovam e ampliam, individual ou coletivamente, o seu
compromisso com os propósitos morais do ensino, adquirem e desenvolvem,
de forma crítica, juntamente com as crianças, jovens e colegas, o
conhecimento, as destrezas e a inteligência emocional, essenciais para uma
reflexão, planificação e prática profissionais eficazes, em cada uma das
fases das suas vidas profissionais.

Complementar ao conceito proposto por Day (2001) é a compreensão de que cada etapa do DP apresenta diferentes necessidades de formação e atuação. 0 magistério é uma carreira complexa e exigente, o que torna o início da docência um período de aprendizagem intensa, que requer tempo, dedicação e apoio.

Os professores iniciantes, assim como os experientes, deparam-se com inúmeras situações complexas e desafiadoras na sala de aula, porém, ao contrário dos experientes, os docentes iniciantes possuem um "repertório profissional" menor, o que amplifica os desafios. Logo, o apoio no início da carreira se reveste de especial importância, pois as primeiras experiências e aprendizagens são fundantes dos saberes que os professores constroem (CUNHA, 2005), e é nessa etapa que ocorrem os principais marcos da identidade e do estilo que irão caracterizar o professor ao longo de sua carreira (LIMA, 2004).

Vários autores dedicaram-se a estudar as características do professor iniciante e os desafios por eles enfrentados na inserção profissional (ALARCÃO; ROLDÃO, 2014; MARCELO 
GARCIA, 2010; GIOVANNI; GUARNIERI, 2014; LIMA, 2006; TANCREDI, 2009; VAILLANT; MARCELO GARCIA, 2012), período também conhecido como tempo de entrada na vida profissional docente, fase do começar a "aprender a ensinar" (MARCELO GARCIA, 1999).

A inserção profissional e o choque com a realidade, aliados à necessidade de aprendizagem do ofício, geram insegurança, preocupações, expectativas e sentimentos contraditórios que podem determinar a permanência ou não do iniciante na profissão. Nesse processo, a socialização profissional exerce um papel muito importante. Para o iniciante, ser um bom professor e passar a pertencer ao grupo de profissionais requer, muitas vezes, assumir modos de pensar desse grupo, o que pode levá-lo a se submeter à opinião dos professores experientes e à aceitação acrítica das normas, regras, crenças e valores da maioria.

É comum nas escolas ouvir dos professores mais experientes frases tais como "a teoria, na prática, é outra", acompanhadas da desvalorização das aprendizagens recebidas na formação inicial que, para muitos professores, foram insuficientes para guiar a sua atuação profissional, o que os leva a negar, em sua totalidade, as aprendizagens ali recebidas.

Inseguro diante das suas referências profissionais, a aprendizagem da docência ocorrerá por processos de tentativa e erro, nos quais são experimentados diferentes modelos de ensino. A preocupação principal dos iniciantes é o como ensinar, em geral com pouca reflexão sobre o porquê de suas escolhas pedagógicas. Para bem ensinar, a gestão da sala de aula (controle dos alunos e manutenção da disciplina) e do conhecimento (saber o conteúdo e ensiná-lo de forma a promover a aprendizagem dos alunos) ocupam as principais preocupações dos iniciantes.

Outro fator que gera forte impacto nos professores iniciantes é a percepção do contexto no qual se insere a escola, revelando que esses docentes não foram preparados para atuar com uma clientela diferente da idealizada nos cursos de formação. As experiências vividas como estudantes também exercem uma forte influência nos professores iniciantes e constituem uma fonte de saberes práticos, frequentemente, acionados diante dos desafios da docência.

A inserção profissional do iniciante acontece, em geral, sem apoio formativo, seja por parte das escolas, secretarias de educação ou instituições de ensino superior, e o PTE aqui estudado é uma exceção. A falta de apoio intensifica os desafios enfrentados no processo de inserção profissional, acentuando as dificuldades com que se deparam os docentes no início de sua trajetória profissional.

Considerando os estudos realizados por Alarcão e Roldão (2014), Marcelo Garcia (2010), Flores (2008), Giovanni e Guarnieri (2014), Lima (2006), Tancredi (2009) e Vaillant e Marcelo Garcia (2012), é possivel resumir os seguintes desafios como os principais do início da docência: 
a) os iniciantes são encaminhados para as condições de trabalho mais difíceis, além disso, é comum um deslocamento constante dos professores em início de carreira;

b) o nível de exigência das escolas para os professores iniciantes equipara-se ao dos professores experientes;

c) o isolamento dos colegas e a falta de apoio e assistência diante das diferentes exigências impostas no cotidiano escolar, sejam elas de cunho pedagógico, burocrático, emocional ou social, geram sentimentos de insegurança, frustração e desmotivação;

d) aprendizado com os professores experientes ocorre de maneira assistemática e depende da iniciativa pessoal desses docentes mais experientes;

e) há necessidade de se adaptar a diferentes contextos;

f) o status do professor iniciante é inferior, sendo visto com desconfiança pela escola, pelos pais e pela comunidade. 0 reconhecimento e a elevação no status são adquiridos com a estabilidade funcional;

g) o gerenciamento da sala de aula, a adequação do currículo ao contexto escolar, a motivação dos alunos, o relacionamento com os pais dos alunos e a dificuldade em contextualizar o conhecimento adquirido na formação inicial.

Diante das dificuldades, os jovens professores podem buscar formas criativas e inovadoras para desenvolver suas atividades e superar as dificuldades encontradas (GIOVANN; GUARNIERI, 2014) ou podem desanimar, imitar acriticamente comportamentos de outros professores, alienar-se de seu papel profissional ou abandonar a profissão.

Diante do exposto, a necessidade de considerar as peculiaridades desse momento profissional e de oferecer apoio ao iniciante é clara. Porém, embora diferentes pesquisas, realizadas em diferentes contextos, indiquem tal necessidade, o que se percebe é que "[...] as ações políticas voltadas para a formação de professores têm estado na contramão do que dizem as pesquisas sobre os professores iniciantes na carreira do magistério." (GIOVANNI; GUARNIERI, 2014, p. 71).

Fernnandes (2014), Lima (2004), Mariano (2005, 2006, 2012), Papi e Martins (2010) e Corrêa e Portella (2012) realizaram, em diferentes artigos, revisão de pesquisas sobre o professor iniciante. Os referidos autores apontam, entre outras conclusões, a escassez de pesquisas com foco no professor iniciante. Além disso, muitos estudos abordam as 
dificuldades, os desafios, o choque de realidade e a tentativa de sobrevivência na profissão. Faltam, ainda, como apontam Corrêa e Portella (2012), pesquisas sobre professores iniciantes bem sucedidos, pois é importante conhecer o desenvolvimento profissional desses docentes, o contexto no qual atuam e quais variáveis de foro pessoal, de socialização profissional e de condições de trabalho contribuíram para o seu sucesso na docência. Espera-se, com o presente artigo, oferecer contribuições nesta direção.

\section{CAMINHOS METODOLÓGIICOS DO ESTUDO}

Optou-se, para a análise dos dados, pela utilização da análise de conteúdo temático-categorial. Para Bardin (2007), a análise de conteúdo é um conjunto de técnicas de análise das comunicações que utiliza procedimentos sistemáticos e objetivos de descrição do conteúdo das mensagens. No conjunto das técnicas da análise de conteúdo, a autora cita a análise por categorias como a mais antiga e a mais utilizada. Bardin (2007, p. 199) assim explica a análise de conteúdo categorial:

\footnotetext{
Funciona por operações de desmembramento do texto em unidades, em categorias segundo reagrupamentos analógicos. Entre as diferentes possibilidades de categorização, a investigação dos temas, ou análise temática, é rápida e eficaz na condição de se aplicar a discursos diretos (significações manifestas) e simples.
}

Retomamos o conceito de categorias a partir de Minayo (2010, p. 177), que as define como conceitos classificatórios que se constituem "...] como termos carregados de significação, por meio dos quais a realidade é pensada de forma hierarquizada [...]" para, então, anunciar a escolha de unidades temáticas para a organização e análise dos dados deste artigo.

\subsection{SELEÇÃO DOS CASOS DE ENSINO QUE COMPÕEM O CORPUS DE ANÁLISE}

Foram analisados 219 artigos de quatro anais do encontro Socialização de Práticas Formativas, promovido pela DDPM, publicados através da parceria UFAM/DDPM/SEMED, ${ }^{4}$ na

4 A Revista Mutações é publicada pela UFAM. A DDPM é a instância responsável pela formação dos professores da SEMED/ Manaus. 
Revista Mutações entre os anos de 2016 e 2019. A seleção dos artigos que compõem o corpus de análise deste estudo foi realizada de acordo com os seguintes critérios:

a) os artigos relatavam, explicitamente, a participação no PTE e seu papel na construção da prática pedagógica relatada;

b) os artigos podem ser classificados como casos de ensino.

Para atender ao segundo critério, utilizou-se a definição de Nono e Mizukami (2002, p. 73), para quem "[...] um caso é a descrição de uma situação com alguma tensão que possa ser aliviada; uma situação que possa ser estruturada e analisada a partir de diversas perspectivas; que contenha pensamentos e sentimentos do professor envolvido nos acontecimentos."

Os treze artigos selecionados que atenderam aos dois critérios e são objeto da análise aqui realizada serão apresentados no quadro abaixo.

Quadro 1 - Título, referência e temática central dos artigos analisados

\begin{tabular}{|c|c|c|}
\hline Título do artigo & $\begin{array}{c}\text { Referência } \\
\text { anais/ano de } \\
\text { publicação }\end{array}$ & Temática central \\
\hline $\begin{array}{l}\text { Vivências interativas e } \\
\text { superação de conflitos } \\
\text { interpessoais na Educa- } \\
\text { ção Infantil: um relato de } \\
\text { experiência. }\end{array}$ & $\begin{array}{l}\text { Anais do \|l } \\
\text { Socialização } \\
\text { de Práticas } \\
\text { Formativas } \\
(2016 / 2017)\end{array}$ & $\begin{array}{l}0 \text { texto trata da experiência vivenciada por uma professo- } \\
\text { ra em uma turma de Educação Infantil, tendo por objetivo } \\
\text { socializar as estratégias utilizadas, no intuito de superar as } \\
\text { situações de conflitos entre as crianças e contribuir com as } \\
\text { práticas de docentes que trabalham nesse nivel de ensino. }\end{array}$ \\
\hline $\begin{array}{l}\text { Tutoria educacional: uma } \\
\text { experiência de formação } \\
\text { em serviço no primeiro } \\
\text { período da Educação } \\
\text { Infantil. }\end{array}$ & $\begin{array}{l}\text { Anais do \|l } \\
\text { Socialização } \\
\text { de Práticas } \\
\text { Formativas } \\
(2016 / 2017)\end{array}$ & $\begin{array}{l}0 \text { artigo traz um relato de experiência do processo formativo } \\
\text { da tutoria para uma professora da Educação Infantil e sua } \\
\text { tutora. Tem como pano de fundo da discussão a ação } \\
\text { desenvolvida no projeto Horta escolar em garrafa PET e os } \\
\text { impactos desta atividade na aprendizagem da turma e no } \\
\text { desenvolvimento da prática da professora-tutorada. }\end{array}$ \\
\hline $\begin{array}{l}\text { Formação em serviço: } \\
\text { experiências vivencia- } \\
\text { das por um professor } \\
\text { tutorado. }\end{array}$ & $\begin{array}{l}\text { Anais do \|l } \\
\text { Socialização } \\
\text { de Práticas } \\
\text { Formativas } \\
(2016 / 2017)\end{array}$ & $\begin{array}{l}0 \text { texto relata as experiências vivenciados por um professor } \\
\text { durante a formação no PTE. } 0 \text { autor destaca a contribuição } \\
\text { do Programa para o DP do tutorado, que trouxe mudanças } \\
\text { significativas quanto ao modo de exercer a profissão no } \\
\text { gerenciamento e planejamento do cotidiano da sala de aula. }\end{array}$ \\
\hline
\end{tabular}




\begin{tabular}{|c|c|c|}
\hline Título do artigo & $\begin{array}{l}\text { Referência } \\
\text { anais/ano de } \\
\text { publicação }\end{array}$ & Temática central \\
\hline $\begin{array}{l}\text { A maleta do futuro e } \\
\text { os gêneros textuais: } \\
\text { desdobramentos de um } \\
\text { planejamento reflexivo. }\end{array}$ & $\begin{array}{l}\text { Anais do II } \\
\text { Socialização de } \\
\text { Práticas Formati- } \\
\text { vas (2016/2017) }\end{array}$ & $\begin{array}{l}0 \text { artigo descreve o desenvolvimento do projeto } A \text { maleta da } \\
\text { leitura e os gêneros textuais que teve como objetivo ampliar } \\
\text { e consolidar a capacidade leitora e de escrita dos alunos } \\
\text { do } 4^{\circ} \text { ano do Ensino Fundamental, promovendo situações de } \\
\text { interações que favoreçam o letramento pelo reconhecimento } \\
\text { dos gêneros textuais, diferenciando-os entre si, consolidando } \\
\text { uma rotina de trabalho reflexiva, construtiva e prazerosa. }\end{array}$ \\
\hline $\begin{array}{l}\text { Construindo uma nação } \\
\text { de leitores e escritores: } \\
\text { praticando o protagonis- } \\
\text { mo em sala de aula. }\end{array}$ & $\begin{array}{l}\text { Anais do III } \\
\text { Socialização de } \\
\text { Práticas Formati- } \\
\text { vas (2017/2018) }\end{array}$ & $\begin{array}{l}0 \text { texto discute o protagonismo do professor em sala de } \\
\text { aula e a importância da escola no incentivo à leitura, a partir } \\
\text { do projeto Construindo uma nação de leitores e escritores, } \\
\text { desenvolvido com uma turma de Educação Infantil. } 0 \text { projeto } \\
\text { foi motivado pelo desejo de inserir as crianças pequenas } \\
\text { no mundo da leitura e da escrita, de forma prazerosa, } \\
\text { possibilitando ao estudante e ao educador o protagonista } \\
\text { desta ação. }\end{array}$ \\
\hline $\begin{array}{l}\text { Ampliando o vocabulá- } \\
\text { rio através de textos } \\
\text { literários. }\end{array}$ & $\begin{array}{l}\text { Anais do IV } \\
\text { Socialização de } \\
\text { Práticas Formati- } \\
\text { vas (2018/2018) }\end{array}$ & $\begin{array}{l}\text { A problemática central do texto é a necessidade de ampliar } \\
\text { o vocabulário dos alunos, pois, segundo os autores, os } \\
\text { estudantes apresentavam dificuldades na compreensão de } \\
\text { determinadas palavras. Para atender a esse objetivo, os } \\
\text { professores utilizaram poemas de autores parnasianos e } \\
\text { modernos. }\end{array}$ \\
\hline $\begin{array}{l}\text { Facebook: plano de fundo } \\
\text { para leitura e escrita. }\end{array}$ & $\begin{array}{l}\text { Anais do IV } \\
\text { Socialização de } \\
\text { Práticas Formati- } \\
\text { vas (2018) }\end{array}$ & $\begin{array}{l}\text { Preocupados com a pouca desenvoltura dos alunos na leitura } \\
\text { e na escrita, bem como pela falta de interesse dos alunos } \\
\text { pela leitura e pela escrita, os autores desenvolveram uma } \\
\text { atividade, cujos objetivos foram: a) desenvolver a prática de } \\
\text { leitura e de escrita através de textos veiculados em redes } \\
\text { sociais; b) ativar o conhecimento prévio sobre as redes } \\
\text { sociais mais usadas pelos estudantes; c) relacionar a leitura } \\
\text { destes textos veiculados em redes sociais com outros de } \\
\text { cunho científico, bem como de outros gêneros textuais; d) } \\
\text { despertar o interesse pela leitura e pela escrita nos estudan- } \\
\text { tes, por meio de diversos gêneros textuais apresentados em } \\
\text { redes sociais; e) reescrever os textos postados nas redes } \\
\text { sociais para interpretação, compreensão e funcionalidades. }\end{array}$ \\
\hline $\begin{array}{l}0 \text { uso do cinema como } \\
\text { recurso didático no } \\
\text { ensino de História. }\end{array}$ & $\begin{array}{l}\text { Anais do IV } \\
\text { Socialização de } \\
\text { Práticas Formati- } \\
\text { vas (2018) }\end{array}$ & $\begin{array}{l}0 \text { artigo discute o potencial pedagógico do uso de filmes como } \\
\text { recurso didático nas aulas de História, para maior engaja- } \\
\text { mento dos estudantes com o conteúdo estudado e para o } \\
\text { uso de outras linguagens no ensino. }\end{array}$ \\
\hline
\end{tabular}




\begin{tabular}{|c|c|c|}
\hline Título do artigo & $\begin{array}{c}\text { Referência } \\
\text { anais/ano de } \\
\text { publicação }\end{array}$ & Temática central \\
\hline $\begin{array}{l}\text { Feedback: um processo } \\
\text { de reflexão sobre a } \\
\text { prática docente. }\end{array}$ & $\begin{array}{l}\text { Anais do V } \\
\text { Socialização de } \\
\text { Práticas Formati- } \\
\text { vas (2019) }\end{array}$ & $\begin{array}{l}0 \text { caso discute a experiência do professor durante a partici- } \\
\text { pação no PTE com foco em uma das estratégias formativas } \\
\text { utilizadas: o feedback. }\end{array}$ \\
\hline $\begin{array}{l}\text { Protagonismo discen- } \\
\text { te: uma proposta de } \\
\text { corresponsabilidade e } \\
\text { autonomia na contribui- } \\
\text { ção de uma nova cultura } \\
\text { escolar. }\end{array}$ & $\begin{array}{l}\text { Anais do V } \\
\text { Socialização de } \\
\text { Práticas Formati- } \\
\text { vas (2019/2019) }\end{array}$ & $\begin{array}{l}0 \text { texto relata uma ação formativa cujo objetivo foi promover } \\
\text { a formação das equipes gestoras das unidades de ensino da } \\
\text { SEMED/Manaus, por meio da formação continuada em serviço, } \\
\text { de forma customizada, com foco na melhoria da aprendiza- } \\
\text { gem dos estudantes. Uma das conclusões extraídas dessa } \\
\text { formação foi a necessidade de estreitar a relação dos alunos } \\
\text { com a escola. Assim, foram construídas estratégias com o } \\
\text { intuito de trazer os alunos para o centro dos processos } \\
\text { decisórios, dando a eles o protagonismo a fim de que de- } \\
\text { senvolvam um sentimento de pertença à escola, colaborando } \\
\text { com os processos de melhoria. }\end{array}$ \\
\hline $\begin{array}{l}\text { Relato de experiência: o } \\
\text { Programa Tutoria Educa- } \\
\text { cional e a prática na sala } \\
\text { de aula. }\end{array}$ & $\begin{array}{l}\text { Anais do V } \\
\text { Socialização de } \\
\text { Práticas Formati- } \\
\text { vas (2019) }\end{array}$ & $\begin{array}{l}\text { Os autores relatam os desafios, inseguranças e aprendiza- } \\
\text { gens do professor tutorado, no início de suas atividades em } \\
\text { sala de aula, e a importância da participação no PTE para o } \\
\text { seu DP. }\end{array}$ \\
\hline $\begin{array}{l}\text { A reflexão da prática: } \\
\text { as contribuições da } \\
\text { formação docente com } \\
\text { o uso do lúdico em sala } \\
\text { de aula. }\end{array}$ & $\begin{array}{l}\text { Anais do V } \\
\text { Socialização de } \\
\text { Práticas Formati- } \\
\text { vas (2019) }\end{array}$ & $\begin{array}{l}0 \text { artigo tem por finalidade relatar as experiências vivenciadas } \\
\text { com o uso do lúdico em sala de aula com alunos da Educa- } \\
\text { ção Infantil, no decorrer da formação em serviço do PTE, uma } \\
\text { vez que esse processo possibilitou vivências diversificadas } \\
\text { e desafiadoras durante o trabalho desenvolvido com as } \\
\text { crianças, além de contribuir para o aprimoramento das ações } \\
\text { da professora em sala. }\end{array}$ \\
\hline $\begin{array}{l}\text { Relato de experiência: } \\
\text { formas de trabalhar a } \\
\text { rotina escolar. }\end{array}$ & $\begin{array}{l}\text { Anais do V } \\
\text { Socialização de } \\
\text { Práticas Formati- } \\
\text { vas (2019/2019) }\end{array}$ & $\begin{array}{l}0 \text { caso discute a estratégia adotada para organização da } \\
\text { rotina de uma sala de aula do } 2^{\circ} \text { ano do Ensino Fundamental, } \\
\text { com o objetivo de motivar as crianças a colaborarem com a } \\
\text { construção da rotina, desenvolvendo sua autonomia. }\end{array}$ \\
\hline
\end{tabular}

Fonte: os autores.

\subsection{DEFINIÇÃO DAS UNIDADES TEMÁTICAS E UNIDADES DE REGISTRO}

As Unidades Temáticas foram construidas, paulatinamente, a partir do aprofundamento dos autores na literatura da área, e foram complementadas/modificadas quando da imersão na leitura dos casos de ensino, ou seja, as categorias foram produzidas 
na relação dialética entre a literatura e a produção dos sujeitos. Como Unidades de Registro foram selecionadas dos textos analisados "frases com sentido completo".

Assim, as Unidades Temáticas definidas para a análise dos casos de ensino foram:

a) temática central do caso e a questão/problemática abordada, ou seja, as principais temáticas discutidas;

b) práticas: inovação, mudança das práticas;

c) desenvolvimento profissional: mudança de crenças, concepções e práticas relatadas pelos professores iniciantes.

Uma vez definidas as Unidades Temáticas e a Unidade de Registro, procedeu-se à leitura minuciosa dos artigos/casos de ensino, retirando-se, em seguida, e incluindo na matriz de análise, trechos do material lido, para se realizar as análises.

\section{ANÁLISE DE DADOS}

Resgatando os objetivos propostos, inicia-se a análise discutindo as experiências formativas e a ação docente retratadas nos casos, bem como as reflexões proporcionadas na e a partir das intervenções sobre a prática pedagógica dos professores iniciantes, para, em seguida, discutir os indicadores do DP expressos nos casos analisados.

\subsection{CASOS DE ENSINO: EXPERIÊNCIAS FORMATIUAS E AÇÃO DOCENTE DE PROFESSORES INICIANTES}

Os casos de ensino evidenciados nesta discussão partem da formação do PTE da SEMED/Manaus, conforme descrito no início deste estudo. As narrativas dos professores explicitam a importância dos momentos formativos para o compartilhamento de saberes teórico-práticos e reflexivos, favorecendo o (re)dimensionamento de suas ações no campo educativo. Para Alarcão (2011, p. 56), os casos 
[...] são a expressão do pensamento sobre uma situação concreta que, pelo seu significado, atraiu a nossa atenção e merece a nossa reflexão. São descrições, devidamente contextualizadas, que revelam conhecimento sobre algo que, normalmente, é complexo e sujeito a interpretações. Os casos que os professores contam revelam o que eles ou os seus alunos fazem, sentem, pensam, conhecem. [...] os casos só são casos le não meros incidentes) porque representam conhecimento teórico e assumem um valor explicativo que vai para além da mera descrição.

Os casos de ensino, quando compreendidos pelo seu conceito prático-reflexivo, favorecem a construção de saberes e contribuem para a elaboração de novas práticas, o que, considerando as possíveis soluções dos casos discutidos e das intervenções realizadas, possibilita, a partir das narrativas compartilhadas pelos professores, refletir sobre as ações didáticas e metodológicas que foram eficazes ou não, em contexto concreto de sala de aula, e, assim, redimensioná-las.

A construção de um caso de ensino, relato de experiência ou outra produção escrita, não é uma estratégia formativa prevista na metodologia de TE desenvolvida pela FIS, porém, a análise dos anais do evento Socialização das Práticas Formativas mostra que essa prática contribui para o desenvolvimento profissional do professor, pois, como afirma Carneiro (2017, p. 114), “[...] nossa formação sempre segue este caminho: observa a prática, reflete sobre ela e retorna para ela." Nesse processo reflexivo, a escrita é um recurso potente.

Nos casos de ensino aqui abordados, identificamos uma diversidade de temáticas e análise discutidas nos textos, dentre elas, cultura escolar, gestão participativa, protagonismo do aluno, autonomia, competências do docente, desafios do contexto escolar, reflexão sobre a prática, ludicidade, rotina escolar, planejamento e estratégias de ensino. Desta diversidade temática, selecionamos três temas presentes em todos os casos de ensino e que permeiam as diferentes temáticas acima citadas: o protagonismo e a autonomia dos alunos, o protagonismo e a insegurança dos docentes e a importância do planejamento.

\subsubsection{Protagonismo do discente}

Direta ou indiretamente, todos os casos analisados trazem a importância de proporcionar experiências que levem as crianças e os jovens a assumir o papel de protagonistas. Singer (2017, p. 17), ao tratar da importância do protagonismo do aluno, destaca: “0 estudante é o centro de um processo que deverá levá-lo ao desenvolvimento em suas diversas dimensões - intelectual, afetiva, corporal, social, ética. Tal processo tem como ponto de partida e de chegada a autonomia." Porém, ressalta a autora, a conquista desta autonomia 
parte da liberdade de escolha dos estudantes que não pode acontecer de forma espontânea e improvisada, mas "[...] a partir de um rigoroso processo de aprendizado de organização e planejamento orientado por seus educadores." (SINGER, 2017, p. 17).

Um exemplo do planejamento de ações didático-pedagógicas com foco no desenvolvimento do protagonismo e da autonomia das crianças é trazido no artigo Tutoria Educacional: uma experiência de formação em serviço no primeiro período da Educação Infantil (FERREIRA; FIGUEIRED0, 2016).

Ferreira e Figueiredo (2016, p. 109-110) relatam os quatro momentos desenvolvidos no projeto Horta escolar em garrafa PET:

$1^{\circ}$ Momento: o projeto iniciou com a participação direta dos pais, pois eles foram os responsáveis em trazer as garrafas pet devidamente preparadas (cortadas no formato combinado previamente) e a comunidade forneceu a terra preta [...] As crianças, em sala de aula, assistiram a um vídeo, que de forma dinâmica e divertida explicou a importância da reciclagem enfatizando a garrafa PET. Em outro vídeo, foi possível abordar os elementos importantes para o desenvolvimento da planta (terra, água e sol) bem como, o passo a passo de como plantar.

$2^{\circ}$ Momento: 0 DIA DO PLANTIO. Nessa ação foi organizada a saída da turma para o jardim da escola, selecionado para a organização da horta.

$3^{\circ}$ Momento: diariamente foi definido junto com a turma quem iria ajudar na rega da horta.

$4^{\circ}$ Momento: 0 DIA DA COLHEITA. Esse foi um dia de muita ansiedade para a turma. Cada criança pegou seu saquinho e colheu parte do coentro para ser utilizado na merenda escolar. Entregaram diretamente na mão da manipuladora de alimentos e em seguida cada um recebeu sua garrafa com o restante da plantação para levar para casa. A alegria no olhar e cada expressão deles foi muito motivador e as crianças diziam: "fui eu que plantei". As outras crianças da escola também queriam uma garrafa com "plantinha" para levar para casa e esse foi momento único.

Para além da autonomia e do protagonismo das crianças, infere-se, a partir dos fatos relatados, que o projeto Horta escolar em garrafa PET desenvolveu várias outras habilidades, como a capacidade de trabalhar em grupo e o autocontrole, necessário para esperar "a sua vez" na hora do plantio, da rega e da colheita. Esse projeto propiciou à docente tutorada adquirir confiança e construir saberes sobre a organização da rotina escolar, resolução de conflitos, desenvolvimento da confiança e do trabalho coletivo com os alunos, contribuindo para a construção do seu repertório profissional.

Outro exemplo de texto voltado para o protagonismo discente foi escrito por Odilon Filho, Santos e Silva (2019). Os registros narrativos do caso Protagonismo Discente: uma proposta de corresponsabilidade e autonomia na contribuição de nova cultura escolar, desenvolvidos pelos professores e formadores do Programa de Tutoria Educacional, partiram 
da necessidade de inserir os alunos nas decisões realizadas pela gestão da escola, considerando os processos formativos como caminhos desveladores de saberes. Segundo os autores, a gestão participativa é um fator determinante para o desenvolvimento das ações afirmativas na escola, ressaltando a importância dos alunos como protagonistas para as mudanças na cultura escolar.

Os autores deste caso de ensino discutem, ainda, a compreensão da formação como espaço de compartilhamento de saberes e reflexões da/na prática. Revelam a autonomia e a responsabilidade socioeducativas estabelecidas pelos momentos dialógicos como determinantes para a constituição de ações práticas, ao tempo em que apontam que esses espaços de formação quebram barreiras de paradigmas tradicionais e os auxiliam no desenvolvimento de ações diretivas e afirmativas mediadas pelo (re)dimensionamento de ações gestoras alicerçadas na participação dos alunos, favorecendo a ressignificação da prática e do protagonismo juvenil.

\subsubsection{Protagonismo do professor: inseguranças, incertezas e construção do repertório profissional}

Os professores iniciantes, tal como os professores experientes, deparam-se com muitas tarefas e responsabilidades, porém encontram-se em um momento de construção do seu repertório profissional, aprendendo a ensinar enquanto ensinam e desenvolvem sua identidade profissional. Para esses jovens profissionais, o início da docência pode ser mais difícil e exaustivo por não terem os saberes da experiência, e sofrerão muito mais se não tiverem suporte e apoio da gestão da escola e da rede de ensino.

Nessa direção, como afirma Carneiro (2017, p. 12) no texto Formação em serviço: experiências vivenciadas por um professor-tutorado, "[...] o tutoramento nos traz um oásis em meio ao deserto de incertezas quanto à prática docente." Bem ressalta Imbernón (2010, p. 32), quando afirma: "Para introduzir certas formas de trabalho na sala de aula é fundamental que os professores sejam apoiados por seus colegas ou por um assessor externo durante as aulas." A insegurança e as incertezas diante do cotidiano da sala de aula ameaçam o protagonismo docente, e a tutoria, como um lugar possivel para experimentações seguras, fortalece a confiança do professor em suas habilidades e competências.

Santos e Brandão (2018, p. 14), em Construindo uma nação de leitores e escritores: praticando o protagonismo em sala aula, ressaltam a importância de um par experiente no desenvolvimento da autonomia e do protagonismo docente: 


\begin{abstract}
Diante da expectativa de aprimoramento da prática pedagógica voltada para o protagonismo do estudante e a partir da formação em serviço oferecido pelo Programa de Tutoria Educacional com sessões formativas e dos seus desdobramentos gerados a partir da ação - reflexão - ação, a professora encontrou $\circ$ apoio necessário para experimentar seu protagonismo em sua prática pedagógica. E desta forma, o projeto 'Construindo uma Nação de Leitores e Escritores' foi motivado pelo desejo de inserir as crianças pequenas no mundo da leitura e da escrita de forma prazerosa, possibilitando ao estudante e educador, o protagonista desta ação.
\end{abstract}

Como já mencionado, o protagonismo implica o planejamento das ações e intervenções pedagógicas. A importância do planejamento da rotina escolar, das sequências didáticas com foco no aluno, também foi uma temática presente nos casos de ensino analisados, conforme será discutido a seguir.

\title{
5.1.3 A importância do planejamento para alcançar os objetivos de aprendizagem
}

Fonseca (2017, p. 114) destaca a importância do planejamento como "[...] dimensão que fundamenta todo o processo educativo e para o qual o educador deve estar preparado." Nos treze textos analisados, observa-se a intenção dos professores de desenvolver atividades inovadoras, usando estratégias diferenciadas e significativas para os alunos, como podemos observar no caso de ensino $A$ maleta do futuro e os gêneros textuais: desdobramentos de um planejamento reflexivo (FONSECA, 2017).

Neste caso de ensino, a autora relata como objetivos do projeto proporcionar aos alunos "[...] situações de interações que favoreçam o letramento, reconhecendo os gêneros textuais e diferenciando-os entre si; bem como, manter uma rotina de trabalho reflexiva, construtiva e prazerosa." (FONSECA, 2017, p. 115).

0 alcance dos objetivos de aprendizagem pode ser observado, segundo Fonseca (2017), na aprendizagem de crianças que ainda estavam "silabando", e, com a participação no projeto, desenvolveram sua capacidade leitora. Na turma desta professora, oito crianças apresentavam muita dificuldade de leitura, destas; seis já conseguem ler pequenos textos.

Outro caso de ensino que discorre sobre o planejamento e a necessidade de compreensão da rotina escolar para o processo formativo das crianças foi produzido por Costa e Laranjeira (2019) e intitulado Relato de Experiência: formas de trabalhar a rotina escolar. Neste texto, as autoras ressaltam a importância da rotina escolar e do seu planejamento, considerando os diferentes contextos em que as crianças vivem. Realizaram seu trabalho 
docente mobilizados pela autoavaliação, na qual utilizaram os eixos de planejamento, práticas de ensino, gestão de sala de aula e avaliação para construir, conjuntamente, um plano de formação, concentrando-se nas necessidades formativas do professor sempre com atenção na aprendizagem dos estudantes.

Para Costa e Laranjeira (2019), a participação das crianças na organização da rotina escolar favorece a construção da autonomia. A intervenção descrita foi orientada pelos eixos formativos que foram construídos pelo par tutora-tutorada e mediados pelas percepções observadas no decorrer da rotina. 0 compartilhamento de saberes advindos dos encontros formativos a partir das experiências docentes foram sinalizados pelas autoras e indicam transformações significativas nas estratégias de ensino de maneira a sistematizar as ações didático-metodológicas do processo de ensino e aprendizagem, considerando as realidades existentes entre alunos, professores e comunidade em geral, centrando no trabalho coletivo e colaborativo por meio de um planejamento intencionalizado.

\subsection{CASOS DE ENSINO: EXPRESSÕES DO DESENUOLUIMENTO PROFISSIONAL DO PROFESSOR}

Consideram-se como indicadores de DP, na análise dos casos de ensino aqui realizada, mudança de crenças anteriores sobre o ensino e/ou alunos, mudança das teorias pessoais dos professores, mudança de práticas, aprimoramento do raciocínio pedagógico e aprendizagens profissionais relatadas, como expresso por Oeiras e Dinelly (2017), no caso de ensino Vivências interativas e superação de conflitos interpessoais na educação infantil: Um relato de experiência.

Oeiras e Dinelly (2017) relatam que a professora tutorada tinha dificuldades em lidar com os conflitos entre as crianças pois, segundo as autoras, "[...] algumas crianças não haviam se adaptado à rotina da sala de referência e nem atendiam aos combinados, apresentando dificuldades na interação e convivência com as demais." (OEIRAS; DINELLY, 2017, p. 103).

0 primeiro indicador de DP da docente é a mudança de crenças pessoais. A professora recorre à literatura (teoria do desenvolvimento de Piaget) para compreender melhor o comportamento das crianças, inclusive o egocentrismo infantil. A busca por uma ancoragem teórica que subsidie a sua prática contribui para o aprimoramento do raciocínio pedagógico, pois, embora reconhecendo o egocentrismo como uma característica da fase de desenvolvimento das crianças, a professora destaca a importância de oferecer a elas experiências que desenvolvam habilidades para viver em grupo. Para as autoras, é "[...] através das experiências interativas que ela la criançal vai se desenvolvendo e fazendo a 
transição da forma de pensamento centrado no eu para o pensamento descentrado, quando percebe a existência do outro." (OEIRAS; DINELLY, 2017, p. 104).

Destaca-se que, em alguns dos casos de ensino analisados (FONSECA, 2017; SANTOS; BRANDÃO, 2018; SILVA; SILVA, 2019), as aprendizagens profissionais foram relatadas, mas na ótica da aprendizagem das crianças, expressas quando da afirmação da utilização de estratégias diversas, desenvolvimento de sequências didáticas pela primeira vez com relato de alcance dos objetivos de aprendizagem pelos alunos.

Os casos de ensino escritos pelos participantes do PTE aqui analisados estão centrados na ação desses professores em suas salas de aula, com potente valor investigativo e formativo. Porém, aproximando-se da conclusão, alguns apontamentos são importantes para situar o leitor diante da compreensão dos limites e possibilidades do PTE e do recorte aqui realizado.

Teles e André (2019, p. 252) destacam que centrar a FC somente na sala de aula é simplificar o trabalho do professor:

\begin{abstract}
Soma-se a essa ressalva, a importância de avançar para uma formação mais colaborativa (IMBERNÓN, 2010), que envolva toda a escola e contribua para a socialização do iniciante, pois, como sugere Day (2001, p. 211): "0s efeitos da formação contínua têm maior probabilidade de se prolongarem [sic] no tempo se puderem ser apoiados e adaptados aos contextos locais da sala de aula e das escolas".
\end{abstract}

Estudos anteriores que analisaram o PTE (TELES, 2019; TELES; ANDRÉ, 2019; GIMENES; FERNANDES; SILVA, 2018) concluíram que o mesmo promove o DP dos professores e de seus tutorados, mas apontam para a necessidade de maior aproximação com gestores e pedagogos, em uma abordagem de formação centrada na escola e não apenas no DP específico do professor que participa do Programa (GIMENES; FERNANDES; SILVA, 2018), conclusão compartilhada pelos autores deste artigo.

\title{
6 CONCLUSÃO
}

A análise aqui empreendida incide sobre o PD dos docentes, já abordado em outros estudos complementares a esta análise (TELES, 2019; GIMENES; FERNANDES; SILVA, 2018). A análise dos treze artigos que preenchem os critérios para casos de ensino lou seja, descrevem uma situação real, oferecem informações sobre o contexto, os participantes e a situação didática (NONO; MIZUKAMl, 2002), tem um enredo, começo, meio e fim, revelam motivos, 
concepções, falsas concepções, conceitos e (pré)conceitos (MIZUKAM, 2000)), permite-nos afirmar que a experiência no PTE promoveu o DP dos professores tutorados.

Nos casos de ensino analisados, os autores declaram, explicitamente ou não, mudanças de crenças e teorias pessoais dos professores sobre o ensino e/ou alunos, além de mudanças e inovação das suas práticas. Compreende-se que, a definição de uma prática como inovadora ou original, depende do espaço lugar em que são determinadas, ou seja, do contexto socio histórico que elas ocupam.

Os anais dos encontros Socialização de Práticas Formativas realizados pela SEMED/Manaus trazem um retrato das práticas que vêm sendo desenvolvidas nas salas de aulas das escolas públicas municipais. Porém, a análise dos 219 artigos dos anais de quatro ocorrências do evento permite que sejam tecidas algumas críticas que podem contribuir para o aprimoramento de futuras produções escritas.

Inicialmente, aponta-se que a impressão gerada na leitura dos artigos é que a preocupação com o formalismo da escrita acadêmica parece tolher a presença dos autores, de suas experiências e aprendizagens, no texto, tornando alguns artigos mais próximos de um portfólio de atividades desenvolvidas durante a participação da tutoria do que de artigos científicos, e limitando sua potencialidade para o uso como caso de ensino em situações formativas.

Além disso, falta, em alguns artigos, clareza na descrição da atividade realizada, do porquê das escolhas e decisões tomadas, bem como informações que confirmem o alcance dos objetivos traçados. Mesmo os artigos considerados casos de ensino carecem de um aprofundamento descritivo, e o aprofundamento de informações contribuiria para o enriquecimento do material e para sua inclusão em processos formativos da própria tutoria e de cursos de formação inicial e continuada, principalmente na região Norte.

0 potencial formativo dos casos de ensino está na discussão de situações escolares específicas, contextualizadas e situadas, e a expressão das peculiaridades da realidade amazônica nestes textos tem grande valor formativo. Por fim, destaca-se que o resgate desse material pode contribuir para a valorização e para a divulgação desses casos de ensino, ressignificando o valor dessa experiência para os autores como produtores de conhecimento sobre a educação e o ensino, e que oferecem relevante contribuição para a formação dos profissionais da educação, ao aproximar, através de seus textos, professores em formação das situações reais e concretas vivenciadas em sala de aula.

\section{REFERÊNCIAS}

ALARCÃo, I. Professores reflexivos em uma escola reflexiva. 8. ed. São Paulo: Cortez, 2011. 
ALARCÃO, l.; ROLDÃO, M, C. Um passo importante no desenvolvimento profissional dos professores: o ano de indução. Formação Docente: Revista brasileira de pesquisa sobre formação de professores, Rio de Janeiro: GT08/ANPEd, v. 6, n. 11, p. 109-126, ago./dez. 2014. Disponível em: https://revformacaodocente.com.br/index.php/rbpfp/article/view/108. Acesso em: 22 nov. 2020.

BARDIN, L. Análise de conteúdo. Lisboa: Edições 70, 2007.

CARNEIRO, B. L. A. Formação em serviço: experiências vivenciadas por um professor tutorado. In: SOCIALIZAÇÃO DE PRÁTICAS FORMATIVAS DA DIVISÃO DE DESENVOLVIMENTO PROFISSIONAL DO MAGISTÉRIO, 2., 2016, Manaus. Anais [...] Manaus: DDPM, 2016. Revista Eletrônica Mutações: educação na Amazônia e correlação de saberes, Manaus: UFAM, v. 8, n. 14, 2017. Disponível em: https://periodicos.ufam.edu.br/ index.php/relem/article/view/3620. Acesso em: 25 out. 2020.

CORRÊA, P. M.; PORTELLA, V. C. M. As pesquisas sobre professores iniciantes no Brasil: uma revisão. Revista Othar de professor, Ponta Grossa: Universidade Estadual de Ponta Grossa, v. 15, n. 2, p. $223-$ 236, 2012. Disponivel em: http://www.uepg.br/olhardeprofessor. Acesso em: 7 jul. 2014.

COSTA, K. J. S.; LARANJEIRA, R. C. G. S. Relato de experiência: formas de trabalhar a rotina escolar. In: SOCIALIZAÇÃO DE PRÁTICAS FORMATIVAS DA DIVISÃO DE DESENVOLVIMENTO PROFISSIONAL DO MAGISTÉRIO, 5., 2019, Manaus. Anais [...] Manaus: DDPM, 2019. Revista Eletrônica Mutações: caminhos da educação: lições da cidade, do campo e da floresta, Manaus: UFAM, v. 12, n. 19, 2019. Disponivel em: https://https://www.periodicos.ufam.edu.br/index.php/relem/article/view/8129. Acesso em: 25 out. 2020.

CRUZ. G. B.; FARIAS, I. M. S.; HOBOLD, M. Indução profissional e o início do trabalho docente: debates e necessidades. Reveduc: Revista Multilingue do Programa de Pós-graduação em Educação da UFSCar, São Carlos, v. 14, p. 1-15, jan./dez. 2020. Disponivel em: http://www.reveduc.ufscar.br/index.php/reveduc/article/view/4149 Acesso em: 24 jan. 2021.

CUNHA, M. I, (org.). Formatos avaliativos e concepção de docência. Campinas, SP: Autores Associados, 2005.

DAY, C. Desenvolvimento profissional de professores: os desafios da aprendizagem permanente. Porto: Porto Editora, 2001.

FERNNANDES, R. F. Professores iniciantes: o que falam as pesquisas apresentadas no IV Congresso Internacional Sobre Professorado Principiante e Inserção Profissional à Docência. In: ENCONTRO NACIONAL DE DIDÁTICA E PRÁTICA DE ENSINO, 17., 2014, Fortaleza. Anais [...] Fortaleza: UECE, 2014. Disponível em: http://www.uece.br/endipe2014/. Acesso em: 22 nov. 2020.

FERREIRA, A. P.; FIGUEIREDO, P. A. Tutoria educacional: uma experiência de formação em serviço no primeiro período da Educação Infantil. In: SOCIALIZAÇÃO DE PRÁTICAS FORMATIVAS DA DIVISÃO DE DESENVOLVIMENTO PROFISSIONAL DO MAGISTÉRIO, 2., 2016, Manaus. Anais [...] Manaus: DDPM, 2016. Revista Eletrônica Mutações: educação na Amazônia e correlação de saberes, Manaus: UFAM, v. 8, n. 14, 2017. Disponivel em: https://periodicos.ufam.edu.br/index.php/relem/article/view/3620. Acesso em: 25 out. 2020. 
FLORES, M. A. La investigación sobre los primeros años de enseñanza: lecturas e implicaciones. In: MARCELO GARCIA, C. (coord.). El profesorado principiante: inserción a la docencia. Barcelona: Octaedro, 2008. Disponivel em: https://docero.com.br/doc/c5xcv. Acesso em: 22 nov. 2020.

FONSECA, D. N. A. S. A maleta do futuro e os gêneros textuais: desdobramentos de um planejamento reflexivo. In: SOCIALIZAÇÃO DE PRÁTICAS FORMATIVAS DA DIVISÃO DE DESENVOLVIMENTO PROFISSIONAL DO MAGISTÉRIO, 2., 2016, Manaus. Anais [...] Manaus: DDPM, 2016. Revista Eletrônica Mutações: educação na Amazônia e correlação de saberes, Manaus: UFAM, v. 8, n. 14, 2017. Disponivel em: https://periodicos. ufam.edu.br/index.php/relem/article/view/3620. Acesso em: 25 out. 2020.

FUNDAÇÃO ITAÚ SOCIAL. Guia de Tutoria de Área. [S. l.: s. n., [20--]. Disponivel em: http://conteudopublicacoes.com.br/itausocial/assets/af200-14fis_pdf_tut-area_livro2_v13.pdf. Acesso em: 26 jan. 2019.

GATTI, B. et al. Professores do Brasil: novos cenários de formação. Brasilia, DF: UNESCO, 2019.

GIMENES, N.; FERNANDES, F.; SILVA, V. G. (org.). Análise da implantação do Programa Tutoria nas Redes Municipais de Educação de Manaus e Sobral: relatório de pesquisa. São Paulo: Fundação Carlos Chagas, 2018.

GIOVANNI, L. M.; GUARNIERI, M. R. Pesquisas sobre professores iniciantes e as tendências atuais de reforma da formação de professores: distância, ambiguidades e tensões. In: GIOVANNI, L. M.; MARIN, A. J. (org.). Professores iniciantes: diferentes necessidades em diferentes contextos. Araraquara: Junqueira \& Marin, 2014. p. 33-44.

IMBERNÓN, F. Formação continuada de professores. Porto Alegre: Artmed, 2010.

IMBERNÓN, F. Formação docente e profissional: formar-se para a mudança e a incerteza. 6. ed. São Paulo: Cortez, 2006.

LIMA, E. F. A construção do início da docência: reflexões a partir de pesquisas brasileiras. Revista do Centro de Educação: Revista do Centro de Educação da UFSM, Santa Maria, v. 29, n. 2, 2004. Disponivel em: http://coralx.ufsm.br/revce/2004/02/a6.htm. Acesso em: 21 dez. 2018.

LIMA, E. F. (org). Sobrevivências no início da docência. Brasília, DF: Liber Livro Editora, 2006.

MARCELO GARCIA, C. Formação de professores para uma mudança educativa. Porto: Porto Editora, 1999.

MARCELO GARCIA, C. 0 professor iniciante, a prática pedagógica e o sentido da experiência. Formação Docente: Revista brasileira de pesquisa sobre formação de professores, Rio de Janeiro: GT08/ANPEd, v. 2, n. 3, p. 11-49, ago./dez. 2010. Disponivel em: http://formacaodocente.autenticaeditora.com.br. Acesso em: 23 dez. 2018. 
MARIANO, A. L. S. A. A aprendizagem da docência no início da carreira: Qual Política? Quais Problemas? Revista Exitus: publicação contínua do Programa de Pós-Graduação em Educação da Universidade Federal do Oeste do Pará, Belém, v. 2, n. 1, p. 79-94, jan./jun. 2012. Disponível em: http://www.ufopa. edu.br/portaldeperiodicos/index.php/revistaexitus/article/view/67. Acesso em: 23 dez. 2018.

MARIANO, A. L. S. A. A construção do início da docência: um olhar a partir das produções da Anped e do Endipe. 2006. Dissertação (Mestrado em Educação) - Universidade Federal de São Carlos, São Carlos, SP, 2006.

MARIANO, A. L. S. A. Pesquisa sobre o professor iniciante e o processo de aprendizagem profissional: algumas características. In: REUNIÃO ANUAL DA ANPED, 29., 2006, Caxambu, MG. Anais [...] Caxambu, MG: ANPEd, 2005. Disponivel em: http://29reuniao.anped.org.br/trabalhos/posteres/GT08-2119--Int.pdf. Acesso em: 5 nov. 2018.

MINAYO, M. C. S. 0 desafio do conhecimento: pesquisa qualitativa em Saúde. 12. ed. São Paulo: HUCITEC, 2010.

MIZUKAMI, M. G. N. Casos de ensino e aprendizagem profissional da docência. In: ABRAMOWICZ, A.; MELLO, R. R. (org.). Educação: pesquisas e práticas. Campinas, SP: Papirus, 2000. p. 139-161.

MIZUKAMI, M. G. N. et al. Escola e aprendizagem da docência: processos de investigação e formação. São Carlos, SP: Ed. UFSCAR, 2002.

MORICONI, G. M. et al. Formação continuada de professores: contribuições da literatura baseada em evidências. São Paulo: FCC, 2017. Disponível em: http://publicacoes.fcc.org.br/ojs/index.php/textosfcc/ issue/view/340/showToc. Acesso em: 18 jun. 2018.

NONO, M. A. Aprendendo a ensinar: futuras professoras das séries iniciais do Ensino Fundamental e casos de ensino. 2001. Dissertação (Mestrado em Educação) - Universidade Federal de São Carlos, SP, 2001.

NONO, M. A. Casos de ensino e professoras iniciantes. 2005. Tese (Doutorado em Educação) - Universidade Federal de São Carlos, São Carlos, 2005.

NONO, M. A.; MIZUKAMI, M. G. N. Casos de ensino e processos de aprendizagem profissional docente. Revista Brasileira de Estudos Pedagógicos, Brasilia, DF: Inep, v. 83, n. 203/204/205, p. 72-84, jan./dez. 2002. Disponivel em: http://rbepold.inep.gov.br/index.php/rbep/article/view/906/0. Acesso em: 1 jan. 2021.

ODILON FILHO, M.; SANTOS, D. A.; SILVA, A. M. Protagonismo discente: uma proposta de corresponsabilidade e autonomia na contribuição de uma nova cultura escolar. In: SOCIALIZAÇÃO DE PRÁTICAS FORMATlVAS DA DIVISÃO DE DESENVOLVIMENTO PROFISSIONAL DO MAGISTÉRIO, 5., 2019, Manaus. Anais [...] Manaus: DDPM, 2019. Revista Eletrônica Mutações: caminhos da educação: lições da cidade, do campo e da floresta, Manaus: UFAM, v. 12, n. 19, 2019. Disponivel em: https://www.periodicos.ufam.edu.br/index. php/relem/article/view/8129. Acesso em: 25 out. 2020. 
OEIRAS, M. C. S.; DINELLY, V. M. Vivências interativas e superação de conflitos interpessoais na educação infantil: um relato de experiência. In: SOCIALIZAÇÃO DE PRÁTICAS FORMATIVAS DA DIVISÃO DE DESENVOLVIMENTO PROFISSIONAL DO MAGISTÉRIO, 2., 2016, Manaus. Anais [...] Manaus: DDPM, 2016. Revista Eletrônica Mutações: educação na Amazônia e correlação de saberes, Manaus: UFAM, v. 8, n. 14, 2017. Disponivel em: https://periodicos.ufam.edu.br/index.php/relem/article/view/3620. Acesso em: 25 out. 2020.

PAPI, S. de 0. G.; MARTINS, P. L. As pesquisas sobre iniciantes: algumas aproximações. Educação em Revista, Publicação de Faculdade de Educação da Universidade Federal de Minas Gerais, Belo Horizonte, v. 26, n. 3, p. 39-56, dez. 2010. Disponivel em: http://www.scielo.br/pdf/edur/v26n3/v26n3a03. Acesso em: 23 dez. 2018.

SANTOS, V. N.; BRANDÃO, M. R. Construindo uma nação de leitores e escritores: praticando o protagonismo em sala de aula. In: SOCIALIZAÇÃO DE PRÁTICAS FORMATIVAS DA DIVISÃO DE DESENVOLVIMENTO PROFISSIONAL DO MAGISTÉRIO, 3., 2017, Manaus. Anais [...] Manaus, DDPM. 2017. Revista Eletrônica Mutações: educomunicação e linguagem, Manaus: UFAM, v. 9, n. 16, 2018. Disponível em: https://www. periodicos.ufam.edu.br/index.php/relem/article/view/5415. Acesso em: 25 out. 2020.

SHULMAN, J. H. Case methods in teacher education. New York: Teachers College; London: Columbia University, 1992.

SILVA, F. G. R.; SILVA, L. P. C. Ampliando o vocabulário através de textos literários. In: SOCIALIZAÇÃO DE PRÁTICAS FORMATIVAS DA DIVISÃO DE DESENVOLVIMENTO PROFISSIONAL DO MAGISTÉRIO, 4., 2018, Manaus. Anais [...] Manaus: DDPM, 2018. Revista Eletrônica Mutações: diferentes abordagens e o ethos da fala do pesquisador, Manaus: UFAM, v. 10, n. 17 2019. Disponivel em: https://www.periodicos.ufam.edu.br/ index.php/relem/article/view/6652.

Acesso em: 25 out. 2020.

SINGER, H. Pelo protagonismo de estudantes, educadores e escolas. In: LOVATO, A.; YIRULA, C. P.; FRANZIM, R. (org.). Protagonismo: a potência de ação da comunidade escolar. São Paulo: Ashoka/Alana, 2017. p. 14-21.

TANCREDI, R. M. S. P. Aprendizagem da docência e profissionalização. São Carlos, SP: EDUFSCAR, 2009.

TELES, N. C. G.; ANDRÉ, M. E. D. A. 0 Programa de Tutoria Educacional da SEMED/Manaus: possíveis contribuições ao desenvolvimento profissional de professores iniciantes. In: LUNA, S. V.; MOROZ, M. (org.). 50 anos de produção em Psicologia da Educação 2: relatos de pesquisa. Campinas, SP: Pontes Editores, 2019. p. 235-253.

TELES, N. C. G. Formação continuada e desenvolvimento profissional de professores da Educação Básica que participam de um programa de inserção profissional. 2019. Tese (Doutorado em Educação) $\checkmark$ Pontifícia Universidade Católica de São Paulo, São Paulo, 2019. 
VAILLANT, D.; MARCELO GARCIA, C. Ensinando a ensinar: as quatro etapas de uma aprendizagem. Curitiba: Ed. UTFPR, 2012.

Endereço para correspondência: Av. Nossa Senhora do Rosário, 3863, Tiradentes, 69103-1280 Itacoatiara, Amazonas, Brasil; nayanapsy@gmail.com 